\title{
Encuentros: entre la palabra y la imagen'
}

Encounters: between word and image

\author{
MARINA MARCOLIN ${ }^{2}$ \\ Ilustradora \\ Italia \\ http://marinamarcolin.blogspot.com.es/
}

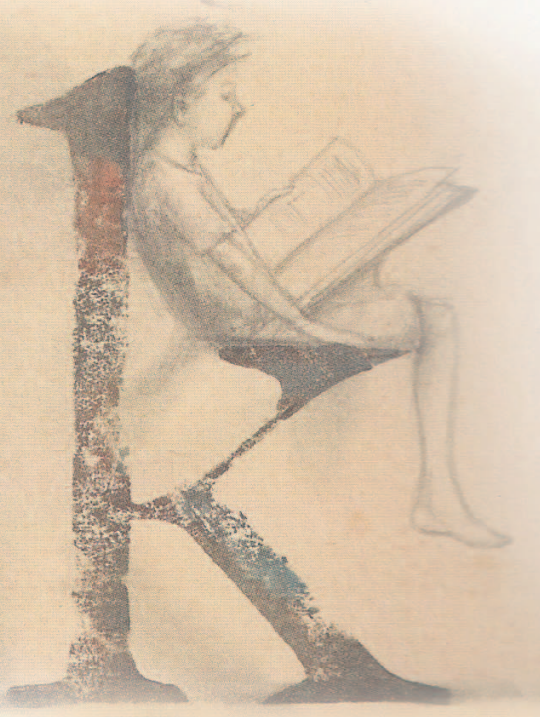

\section{El primer recuerdo...}

unido a la lectura proviene de una habitación, la habitación de cuando era pequeña. Ese espacio no era sólo mío, porque después de una mudanza, habían colocado allí las cosas de estudio de mi padre, entre ellas los libros. Todos los libros de la casa estaban allí, pero no eran libros para niños, ni siquiera libros con ilustraciones, eran sencillamente, libros.

No estaba obligada a leerlos, pero tampoco estaba prohibido cogerlos, por lo que podía abrir cualquier libro y comenzar mi lectura, y aunque no lo entendiera todo podía perderme entre sus páginas e imaginar...

\footnotetext{
I Para citar este artículo: Marcolin, Marina (2012). L’incontro. Alabe 6 [www.revistaalabe.com] (Recibido $04 / \mathrm{IO} / 2 \mathrm{OI} 2 ;$ aceptado OI/II/2OI2)

${ }^{2}$ Marina Marcolin es ilustradora profesional, ha recibido diversos premios como el de Mejor ilustradora Internacional del año 2006, concedido por el Ministerio de Cultura griego. Ha participado en numerosas exposiciones y tiene gran número de libros publicados. Es profesora de ilustración en Vicenza. Le agradecemos su autorización para emplear la ilustración protagonista de la portada de Alabe 6.
} 
Cuando recibo un texto para ilustrar, busco ese recuerdo, ese verdadero acercamiento que me hacía olvidar donde me encontraba (en mi habitación, bajo un árbol o en el patio) y me llevaba al interior de la historia, entre las corrientes del océano, en una antigua casa inglesa o junto a Pinocho, en la Toscana.

Leo y dejo que una palabra o una frase me conduzca a las imágenes, leo sin pensar que lo que haré será para niños, leo como si no supiera dibujar.

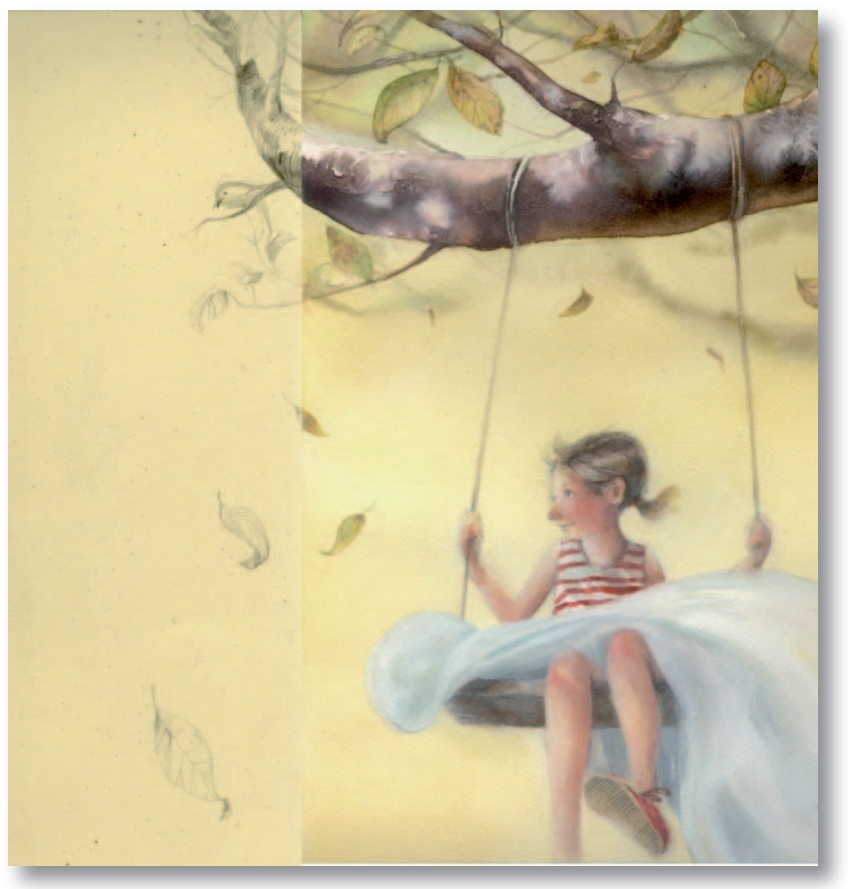

\section{El primer recuerdo...}

unido al dibujo es muy natural y espontáneo, como para cualquier niño.

La pared de la cocina, junto al frigorífico, con los azulejos verdes y naranjas, era la destinada a los dibujos: allí estaban, pegados con celo uno al lado del otro, como una historia sin sentido y llena de colores, divertida, feísima y sobre todo libre.

En el instituto tuve la suerte de asistir a los cursos que deseaba: el liceo artístico y fueron años muy importantes para mi. A esa edad no tenía aún idea de cual sería mi profesión, pero el hecho de dibujar, estaba por encima de todo para mi, me permitía hasta vencer mi gran timidez. Lamentablemente, al finalizar el bachillerato, el dibujo se esfumó, lejos de mis manos y de mis días. Pasé algunos años realizando trabajos que no tenían mucho de "artístico", y así un día con otro, se fue formando un gran vacío dentro de mí. 
El dibujo regresó, tras unos años, despacio, sin hacer mucho ruido, como una tabla de salvación. Como una forma de volver a aprender de nuevo a no temer al mundo, a las personas, a la vida. Lo único que necesitaba era un cuaderno para los bocetos y entonces cualquier cosa recuperaba su esencia, se llenaba de cosas por descubrir. En ese período dibujé y caminé muchísimo, y entonces tuve la certeza de que esto no me abandonaría nunca más.

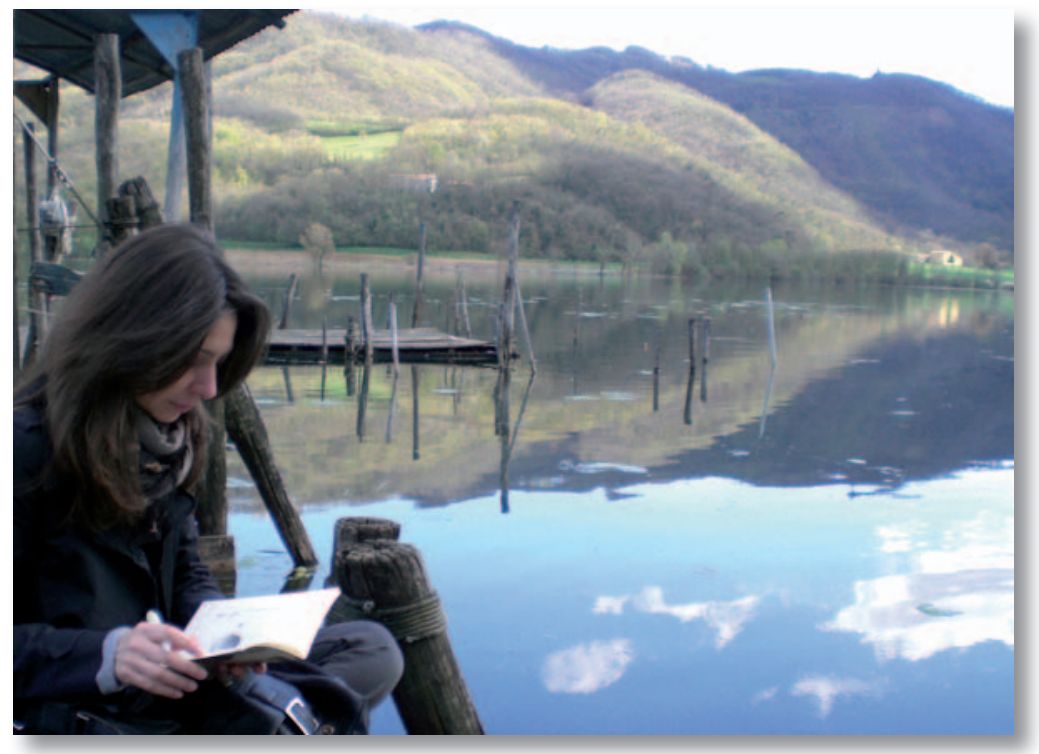

\section{El encuentro...}

con la ilustración llegó un día, en una bellísima exposición que visité por casualidad. No sabía absolutamente nada de libros ilustrados, entre otras cosas, porque de pequeña no teníamos este tipo de libros en casa, por lo que descubrir que era posible unir mis dos grandes pasiones, los libros y el dibujo, fue como si se abriera una puerta de par en par. Era consciente de que no sería fácil, de que debería entender muchas cosas y aprender, mirar, escuchar, equivocarme y trabajar mucho. Paso a paso, para hacer lo que más deseaba.

El camino duró varios años, asistiendo a cursos con ilustradores profesionales, participando en concursos y proponiendo mi carpeta de trabajos a los editores en las ferias del libro. No se consigue la perfección de la noche a la mañana, es más, nunca se consigue, pero se aprende, también a aceptarlo. El oficio de ilustrador es un trabajo muchas veces solitario, por eso ha sido muy importante para mi el intercambiar y relacionarme con otros artistas, con los editores mismos, con sus consejos, todo se revela y sigue revelándose como algo precioso. El enriquecimiento humano y artístico se vive también en las escuelas y en las bibliotecas, en los talleres para niños o en las asociaciones para las que trabajo como profesora de acuarela para adultos, esos que cuando eran niños dejaron de pintar porque pensaban que no serían capaces, son mis preferidos. Enseñando, aprendo muchísimo. 


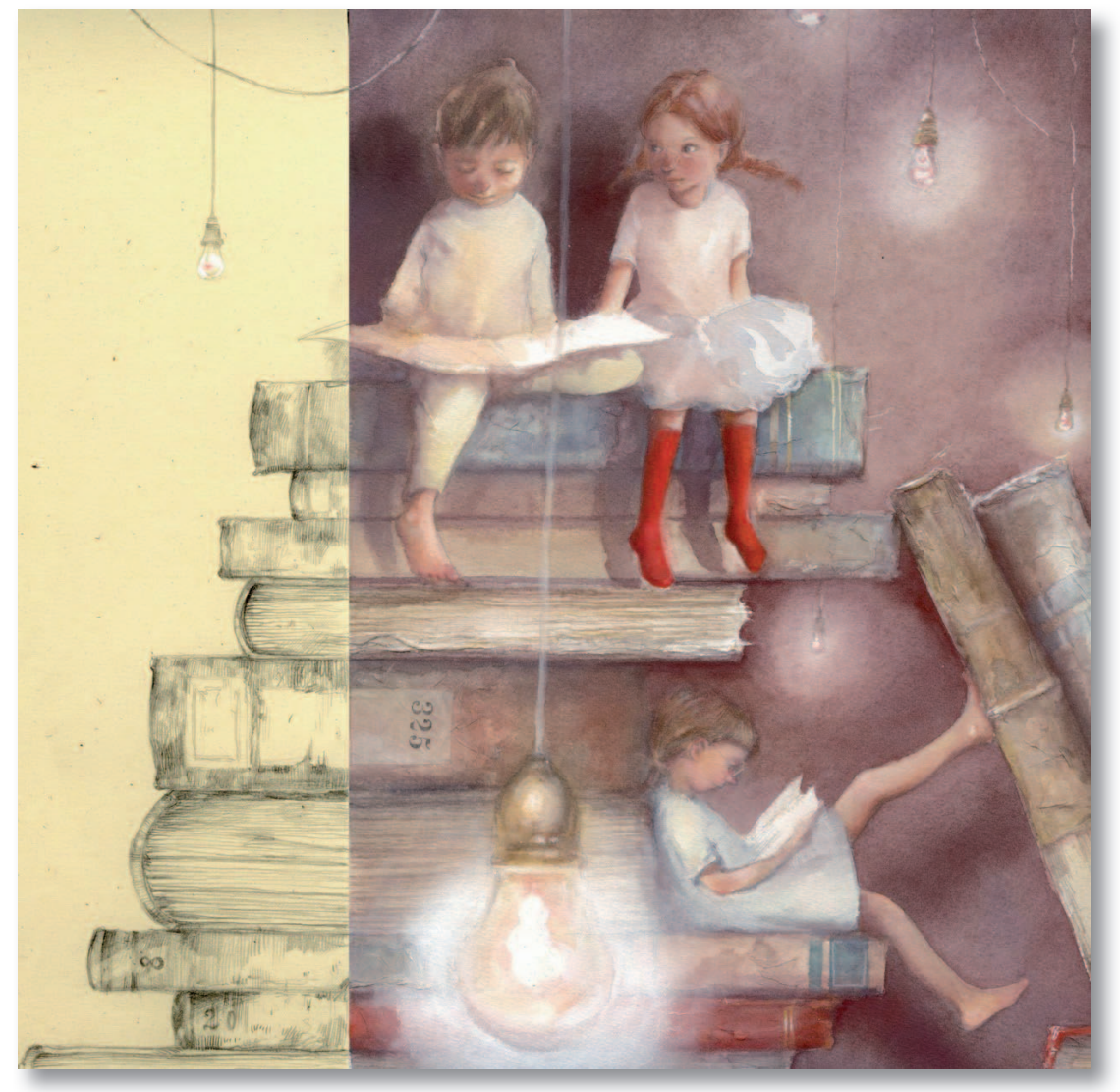

\section{El encuentro...}

con la editorial Kalandraka se produjo en la Feria del libro para niños de Bologna. En los años anteriores a ese encuentro, había tenido la oportunidad de ilustrar una veintena de libros, publicados por editoriales de diferentes países.

Siempre he visto a Kalandraka como una editorial de calidad, siempre atenta a la profundidad y cuidado del libro. El haber tenido la oportunidad de un encuentro con ellos, fue muy especial, un gran privilegio.

Estaba muy emocionada ante la idea de enseñarles mis trabajos, una emoción que te acompaña siempre, aunque lo hayas hecho muchas otras veces. Intentas ser profesional, ciertamente, pero una parte de ti está sobre esa mesa, bajo una especie de juicio, de valoración. Y debemos confiar, en nosotros mismos y en quien está delante de ti. En este caso fui muy afortunada, porque en frente tenía a una persona muy sensible, competente y directa: Lola Barceló Morte, de Kalandraka Italia. Tanto ella como Silvia Pérez Tato se mostraron interesadas en mi trabajo: ¡me sentía realmente feliz!

La oportunidad de trabajar juntas llegó el año siguiente, me llamaron por teléfono durante la Feria de Bologna, porque querían que conociera con la escritora Cristina Falcón Maldonado; fue un encuentro muy importante para mí. Leí su texto, conmovedor y de 
gran sensibilidad, poético y a la vez increíblemente auténtico. Era bellísimo. Se notaba claramente que la persona que había escrito esas palabras había vivido con hondura y sabía exactamente que la palabra "infancia" no es un término abstracto, hecho de teorías, sino un auténtico conjunto de lo vivido, incluido lo más duro, pero lleno de esperanza, jamás un fin en sí mismo.

La experiencia de ilustrar Letras en los cordones fue especial, entre otras cosas porque me sentí muy libre, que no es algo habitual, no sucede con tanta frecuencia. Podía interpretar el texto con un significado completamente personal y escoger los matices y los colores que armonizaban mejor con lo que sentía y desde los primeros bocetos todo se fue manifestando de un modo natural.

El entendimiento y el vínculo, una especie de hilo, con Lola, Silvia y Cristina fue fundamental, se reveló como algo esencial. Una gran profesionalidad y calidad humana que me siguen conmoviendo.

El proceso previo de estudio y preparación del "sabor" que tendrá el libro es para mi la fase más hermosa, que se convierte como en una búsqueda del tesoro entre las líneas del texto y las ilustraciones, una tras otra. Cuando trabajo en un libro, su historia me acompaña a todas partes, no sólo cuando estoy en mi mesa de dibujo.

Lo que me sugiere y las ideas que van surgiendo, provienen del vivir y observar cada día todo lo que me rodea, y cada pequeño detalle es una fuente de inspiración. Lo que se mezcla en la paleta no es el amarillo, el azul o el negro, es la esencia misma de las cosas. Tomas con la punta del pincel el aire, la luz, un rostro o un encuentro y lo plasmas sobre el papel.

Me resulta difícil explicar esta magia con las palabras, quizás para mi es más sencillo dibujarla.

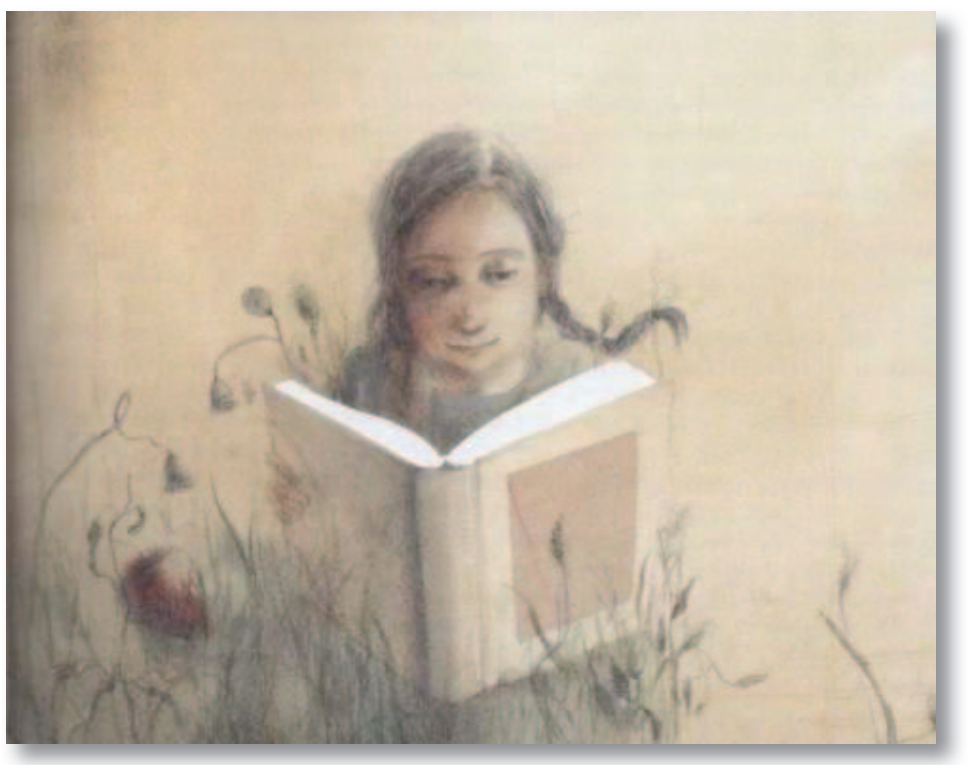

